\title{
Assessing the Ideal Valve Size During Aortic Valve Replacement with Rapid Deployment Bioprosthetic Valves. Is Intraoperative Transesophageal Echocardiogram Reliable?
}

\author{
Michael Magarakis ${ }^{1}$, Panagiotis Sarris-Michopoulos ${ }^{2}$, Ali Al-Alameri ${ }^{1}$, Alejandro Macias ${ }^{1}$, \\ Alvaro Montoya ${ }^{1}$, Evan Markell ${ }^{1}$, and Julio Benitez ${ }^{3}$ \\ ${ }^{1}$ University of Miami Department of Surgery \\ ${ }^{2}$ University of Miami School of Medicine \\ ${ }^{3}$ University of Miami Health System
}

February 23, 2022

\begin{abstract}
Objective: To describe our experience with using intraoperative Transesophageal Echocardiography (TEE) to assess the size of the rapid deployment prosthetic valves by measuring the native aortic annulus. Methods: Retrospective review of single institution series of patients undergoing Aortic Valve Replacement with Rapid Deployment Bioprosthetic Valves. Included were patients who had their native aortic valve replaced either isolated or as part of any additional procedure. The aortic annulus was measured prior to initiation of the operation using TEE. An analysis was conducted between Echocardiographic annular measurements and actual implanted valve sizes. Results: Forty patients underwent rapid deployment valve implantation in the aortic position. Of these, $32.5 \%$ of patients had the same size valve as the measured aortic annulus, $40 \%$ of patients had a valve implanted that was $1 \mathrm{~mm}$ different, and $25 \%$ of patients had $2 \mathrm{~mm}$ difference. One patient (2.5\%) was found to have an aortic annular measurement of $3 \mathrm{~mm}$ less than the actual implanted valve. The mean annular size based on intraoperative TEE was $23.5 \mathrm{~mm}$ (range: $21-28 \mathrm{~mm}$, sdv: 1.8). The mean valve size implanted was $23.7 \mathrm{~mm}$ (range: $21-27 \mathrm{~mm}$, sdv: 1.9 ). There was no statistically significant difference between the mean annular measurement and the valve size selected $(0.2 \mathrm{~mm}, \mathrm{p}=0.50)$. Conclusion: TEE can further enhance valve sizing and guidance through a proper and safe deployment. Although evident in our experience, larger scale studies are needed to further elucidate conclusions on the importance of avoiding under-sizing valves.
\end{abstract}

\section{Hosted file}

Assessing the Ideal Valve Size During Aortic Valve Replacement with Rapid Deployment 2.19.22.docx available at https://authorea.com/users/322287/articles/557471-assessing-the-ideal-valvesize-during-aortic-valve-replacement-with-rapid-deployment-bioprosthetic-valves-isintraoperative-transesophageal-echocardiogram-reliable 